\title{
Comprehensive Overview and Treatment Update on Hair Loss
}

\author{
Katlein França ${ }^{1}$, Thiago Saldanha Rodrigues ${ }^{2}$, Jennifer Ledon ${ }^{1}$, Jessica Savas ${ }^{1}$, Anna Chacon ${ }^{1}$ \\ ${ }^{1}$ Department of Dermatology \& Cutaneous Surgery, University of Miami Miller School of Medicine, Miami, USA; ${ }^{2}$ Department of \\ Oncologic Surgery, Instituto do Câcner Doutor Arnaldo Vieira de Carvalho, São Paulo, Brazil. \\ Email: kf.dermatologia@gmail.com
}

Received April $1^{\text {st }}, 2013$; revised May $3^{\text {rd }}, 2013$; accepted May $10^{\text {th }}, 2013$

Copyright (C) 2013 Katlein França et al. This is an open access article distributed under the Creative Commons Attribution License, which permits unrestricted use, distribution, and reproduction in any medium, provided the original work is properly cited.

\begin{abstract}
Hair loss is one of the most common complaints among all patients consulting a dermatologist and is usually associated with severe psychological disturbances, distress and symptoms of depression. [1-3]. It can be temporary or long lasting. Diagnosis of hair loss is based on detailed clinical history, physical exam, clinical diagnostic tests, laboratory testing, and scalp biopsy, which may be necessary to confirm some diagnoses. This article presents an overview of the most common clinical causes of hair loss and provides updated information on the current available therapeutic options for these disorders.
\end{abstract}

Keywords: Hair Loss; Alopecia; Telogen Effluvium; Trichotillomania

\section{Introduction}

Hair loss is one of the most common complaints among all patients consulting a dermatologist and is usually associated with severe psychological disturbances, distress and symptoms of depression [1-3]. It can be temporary or long lasting. Diagnosis is based on detailed clinical history, physical exam, clinical diagnostic tests, laboratory testing, and scalp biopsy, which may be necessary to confirm some diagnosis [4-6]. The pathophysiology of such disorders may include infectious, nutritional, congenital, autoimmune, or environmental causes. The most common forms of nonscarring alopecia are androgenic alopecia, telogen effluvium, and alopecia areata. Scarring alopecia is caused by trauma, infections, discoid lupus erythematosus, or lichen planus. Other disorders include trichotillomania, traction alopecia, tinea capitis, and hair shaft abnormalities [7,8]. An adequate evaluation and management is essential for appropriate patient care and successful treatment [3].

This article presents an overview of the most common clinical causes of hair loss in women and provides updated information on the current available therapeutic options for these disorders.

\section{Clinical History}

A detailed clinical history is essential to make a diagno- sis. The patient may provide information regarding the use of medications, illnesses, recent surgeries and general anesthesia, hormonal disease, thyroid disease, diets and weight loss, history of important psychological distress and family history of hair loss. The duration and location of the hair loss should also be asked. Patients may be referred for focal patches or more diffuse hair loss [6-8].

\section{Physical Exam}

Once the history of the patient is documented, the patient should be carefully examined. First the skin of the scalp should be examined. Note the color of the scalp, presence and distribution of hair follicles, scaling or evidence of scarring [8]. The hair density should also be noted if it is normal or decreased. To evaluate the severity of hair shedding, the "pull test" can be performed. This simple test can determine the ongoing activity and severity of hair loss. The physician should grab onto 20 - 30 hairs with his/her fingers and gently pull on them. If produces more than 10 hairs is suggestive of increased hair loss $[2,4]$. A hair sample should be collected for microscopic analysis. Light microscopy of the hair is an important tool for several disorders affecting the scalp and hair, including genodermatoses and other syndromes [9-11].

\section{Understanding the Hair Cycle}

Hair follicles cycle through anagen (growth), catagen (re- 
gression) and telogen (resting) phases (Table 1). Understanding this process is clinically important, since the vast majority of patients with hair disorders suffer from an undesired alteration of hair follicle cycling $[12,13]$. Anagen hair loss occurs due to disorders that stop the mitotic activity of anagen follicles, such as alopecia areata and drugs $[4,14]$. On the other hand, telogen hair loss occurs due to injuries that may cause premature follicle telogenization $[4,15]$.

\section{Alopecia}

\subsection{Androgenetic Alopecia}

Androgenetic alopecia (AGA) is the most common form of hair loss. When it affects women, it leads to diffuse alopecia over the mid-frontal scalp (female pattern hair loss) [16]. This process is a result of hair follicle miniaturization within follicular units. It represents a progressive reduction in diameter, pigmentation and length of the hair shaft $[4,17]$. These miniaturized hairs are the hallmark of AGA. Most women with AGA have normal menses and pregnancies. 18 This disorder is induced by androgens in genetically susceptible persons. These patients present hair follicles with increased $5 \alpha$-reductase activity and dihydrotestosterone (DHT) levels. In these genetically susceptible hair follicles, the DHT binds to the androgen receptor and the hormone-receptor complex, activating the genes responsible for the transformation of the normal hair follicle in miniaturized follicles $[18,19]$. The reduction in the number of terminal fibers per follicular unit will produce a diffuse alopecia [17]. The impact of androgenetic alopecia is predominantly psychological. While men anticipate age-related hair loss, the same process in women is usually unexpected and unwelcome at any time [20,21] (Figure 1).

Association with thyroid disorders is suggested by some authors, but alopecia is unaffected by thyroid substitution [21]. This disorder can be precipitated or worsened by conditions that induce telogen effluvium such as postpartum telogen effluvium. If associated with hirsutism and acne, AGA can be a sign of hyperandrogenism in premenopausal women [4]. Pharmacological-containing estrogens (contraception) have a beneficial effect on such alopecia, probably through different mechanisms: anti-androgen effect increased and proliferative effect of

Table 1. Hair cycle phases.

\begin{tabular}{ll}
\hline Anagen & $\begin{array}{l}\text { The follicles produce the hair shaft. Duration ranges from } \\
\text { two to seven years. Up to } 85 \% \text { of the hair is in this phase } \\
\text { at one time. }\end{array}$ \\
Catagen & $\begin{array}{l}\text { Transitional phase that lasts two to three weeks which } \\
\text { precedes the resting telogen phase }\end{array}$ \\
Telogen & $\begin{array}{l}\text { Hair production is absent. Up to } 15 \% \text { of hair is in this } \\
\text { phase at one time and it can last } 3 \text { months. }\end{array}$ \\
\hline
\end{tabular}

dermal papilla cells [22]. But contraceptives that contain androgenic progestins like nortestosterone-derivates levonorgestrel may induce or worsen this condition $[4,22,23]$. Levonorgestrel intrauterine device has been described as cause of hair loss [24].

\subsection{Alopecia Areata}

Alopecia areata (AA) is a nonscarring autoimmune, inflammatory scalp, and/or body hair loss condition [25]. It affects up to $2 \%$ of the population and it is characterized by patchy hair loss (Figure 2). It can affect the entire scalp (alopecia totalis) or cause loss of all body hair (alopecia universalis) [4,26]. Histopathology shows an increased number of the catagen and telogen follicles and the presence of an inflammatory lymphocytic infiltrate in the peribulbar region [25].

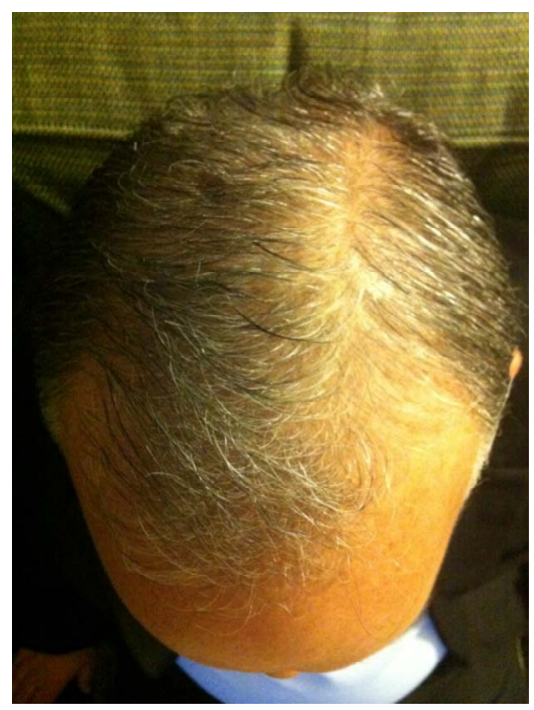

Figure 1. A 55-year-old male presenting androgenetic alopecia.

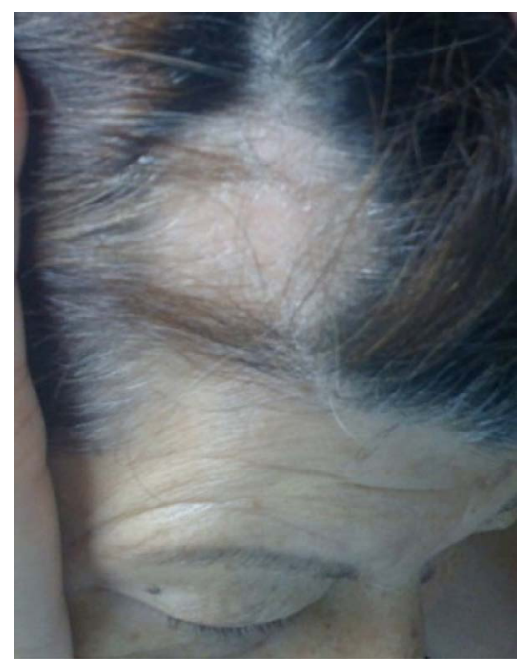

Figure 2. Alopecia areata in a 64-year-old female. 
Many factors are under investigation to clarify the pathogenesis of AA. Nonspecific immune and organ-specific autoimmune reactions and genetic constitution are possible causes [27,28].

One of the most discussed ideas is that genetically predisposed individuals present an autoimmune $\mathrm{T}$ cell-mediated-reaction against the hair follicle [28]. This process may be caused by different triggering factors, such as viral infections and stress [4,29]. It can be associated with other autoimmune disorders, such as thyroid disease [4].

The influence of psychological factors in the development, evolution and therapeutic management of alopecia areata is documented by several authors. The comorbidity of psychiatric disorders, mainly depression, generalized anxiety disorder and phobic states, is high [30,31].

Postoperative alopecia areata following surgery has been reported after gynecologic and cardiac procedures. Although pressure-induced ischemia is the most likely etiological factor, a study conducted by Khalaf and colleagues showed that these patients might also present with psychiatric comorbidities, questioning the real etiology of AA in these patients [32].

\subsection{Chemotherapy Induced Alopecia}

Most cytotoxic anticancer chemotherapy agents induce alopecia by ablating the rapidly dividing epithelium of the hair follicle. The overall incidence of chemotherapyinduced hair loss is estimated to be $65 \%$ and the severity and prevalence of this type of hair loss is related to the selected chemotherapeutic agent and treatment protocol [33]. Chemotherapy-induced anagen effluvium is usually reversible, but it's known that certain chemotherapy regimens can cause permanent alopecia. In these cases, moderate to very severe hair thinning and altered texture may be seen when hair regrows [34]. Although it is transient, chemotherapy-induced alopecia it is often psychologically devastating, especially for women $[35,36]$ (Figures 3 and $\mathbf{4}$ ).

\subsection{Trichotillomania}

Trichotillomania, also known as hair pulling disorder, is an impulse-control disorder that affects at least 3.7 million people in the United States and results in marked functional impairment $[37,38]$. This disease is characterized by an irresistible desire to manipulate and pull out the hair [4]. The disorder typically onsets in childhood either in preschool or in the preadolescent years and is up to seven times more commonly found in the pediatric population than in adults [39]. The disorder may begin as a habit, similar to nail-biting or thumb-sucking [40]. On physical examination, irregular patches of hair loss with bizarre borders can be observed. Inside of these patches, short and broken hairs with variable lengths are evident

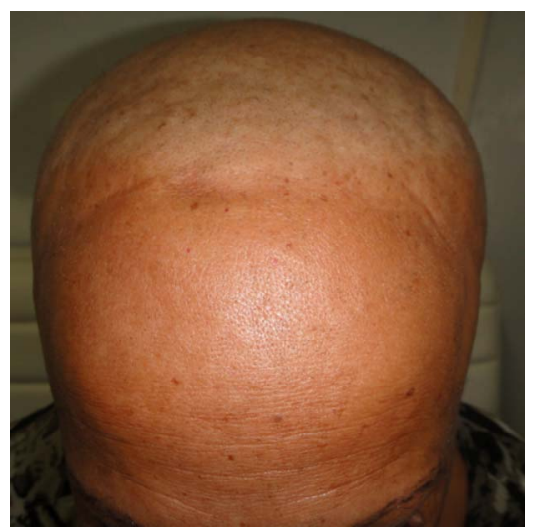

Figure 3. Chemotherapy induced alopecia.

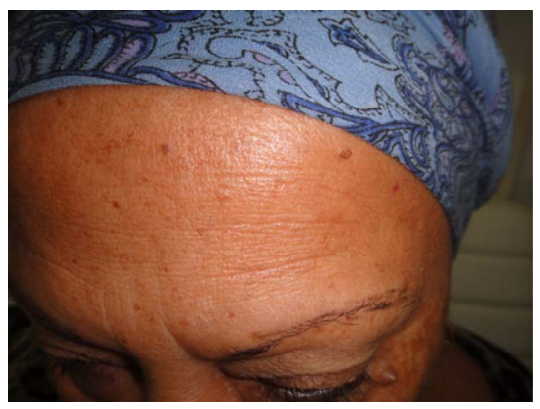

Figure 4. Eyebrow hair loss in a female patient undergoing chemotherapy.

[4]. Appropriate psychoeducation and minimally invasive behavioral treatments are possible interventions for this common disorder [41,42].

\section{Telogen Effluvium}

Telogen effluvium (TE) is an increased loss of normal club hairs that occurs by a perturbation of the hair cycle [43]. It was first described by Kligman in 1961 and his hypothesis was that whatever the cause of hair loss, the follicle tends to behave in a similar way, causing premature termination of anagen $[43,44]$. The true incidence is unknown because many cases are subclinical [45]. Common causes of TE include iron deficiency, drugs and stress (Table 2).

\subsection{Acute Telogen Effluvium}

The first description of classic telogen effluvium was an acute onset hair loss 2 - 3 months after a triggering event such as surgical trauma or high fever [46]. Other known causes include drugs, stress, fever, weight loss, hypothyroidism, hyperthyroidism, and other disorders that may cause inflammation of the scalp, such as contact dermatitis $[45,47]$. In cases where no cause is found, screening for thyroid disease, antinuclear antibody and syphilis should be performed. Acute TE does not usually produce visible alopecia; the patient often complains that the hair 
Table 2. Common causes of telogen effluvium.

Nutritional Deficiency
Stress
Fever
Drugs
Postpartum
Hypothyroidism/hyperthyroidism
Hepatic failure
Chronic renal failure
Idiopathic

is falling out. Daily shedding of 100 to 200 telogen hairs can be observed in severe cases [4].

\subsubsection{Nutritional Deficiency}

One of the most common causes of hair loss in premenopausal women is nutritional deficiency of iron. Screening for serum ferritin and hemoglobin should be performed to clarify the possible cause of hair loss in this population [48]. Iron supplementation is recommended when levels of ferritin are below $30 \mathrm{ng} / \mathrm{ml}$ [4]. Severe protein, caloric restriction, vitamin D deficiency, zinc deficiency and chronic starvation can also induce diffuse telogen hair loss $[49,50]$.

\subsubsection{Stress}

Evidence of the data suggests that neurotransmitters, neurohormones, and cytokines released during the stress response may also significantly influence the hair cycle [51]. Arck and colleagues provided further evidence for existence of a "brain-hair follicle axis". This theory says that audiogenic stress also induces significant changes in actively growing hair follicles and promotes their transition into the involution phase [52].

\subsubsection{Drugs}

Hair loss can be an adverse effect of a large number of drugs. The severity of alopecia will depend on the drug and individual predisposition. While some drugs will produce only hair abnormalities others will produce severe hair loss, even with appropriate dosages. Drugs affect anagen follicles by two different processes: precipitating the follicles into premature rest (telogen effluvium) or inducing an abrupt cessation of mitotic activity in rapidly dividing hair matrix cells (anagen effluvium). Anticoagulants, retinol, interferon, antihyperlipidemic drugs are just a few examples of drugs that can induce telogen effluvium [52]. Hair loss from the scalp, eyebrows, and pubic area was identified as a possible adverse effect of most psychotropic medications. This process is usually reversible after interruption of treatment [53].

\subsubsection{Postpartum}

Postpartum hair loss usually starts two to four months after delivery and may last six months to one year [55]. Although the prevalence of postpartum alopecia is not known, it is believed to be common. Patients without nutritional deficiencies or other diseases will achieve complete recovery after an additional six to nine months, but physicians should keep in mind that this condition can precipitate the development of alopecia areata in predisposed patients [54,55]. The hair loss is always diffuse but never total. Some patients may experience slower growth with decreased hair density [55,56].

\subsection{Chronic Telogen Effluvium}

This condition is characterized by hair shedding lasting longer than 6 months, and with a fluctuating chronic course over many years. It is idiopathic and usually a trigger cannot be identified $[2,4]$. The diagnosis of chronic telogen effluvium is made by the exclusion of causes of diffuse telogen hair loss, including androgenetic alopecia [8]. Scalp pain and reduced hair density is commonly reported by patients.

\section{Treatment}

\subsection{Androgenetic Alopecia}

\subsubsection{Topical Minoxidil}

Topical Minoxidil is now the most widely recommended treatment for androgenetic alopecia. It is available in $2 \%$ and $5 \%$ solutions for hair loss. The $2 \%$ solution is the only one approved by FDA for use in female patients. It stimulates new hair growth and helps stop the loss of hair in individuals with androgenetic alopecia (AGA) [57-59]. Side effects include a transient shedding during the first 4 months of use and contact dermatitis [60].

\subsubsection{Finasteride}

Finasteride is a synthetic type-2 $5 \alpha$-reductase inhibitor and has been studied by several authors as a treatment for female pattern hair loss. A review study published in 2011 shows that objective evidence of efficacy is limited, but it may be considered as a treatment for patients who fail topical minoxidil [61]. Finasteride is well tolerated; however, premenopausal patients must adhere to reliable contraception while receiving it. The dosage of 2.5 $\mathrm{mg} /$ daily seems to show better results when compared to $1.0 \mathrm{mg} /$ daily. It is contraindicated in pregnancy, due to known teratogenicity. For men, the dosage is $1 \mathrm{mg}$ once a daily [62].

\subsection{Anti-Hormonal Therapy}

Reviews suggest that anti-hormonal therapy is helpful in treating female pattern alopecia in some women who 
have normal hormone levels.

Spironolactone is an aldosterone antagonist employed in clinical practice as a potassium-sparing diuretic. It reduces adrenal androgen production and exerts competitive blockade on androgen receptors in target tissues [63]. This medication has been used off-label in female pattern har loss for over 20 years and it has been shown to arrest hair loss progression with a long-term safety profile. It should not be used in pregnancy due to its teratogenic effects [64].

Cyproterone acetate is an androgen receptor blocker with strong progestational activity and a weak glucocorticoid action. It seems to decrease hair shedding, but does not seem to promote regrowth [65]. The dose required for premenopausal women is $100 \mathrm{mg}$ daily for 10 days of each menstrual cycle and postmenopausal women should use $50 \mathrm{mg}$ daily continuously. Sinclair and colleagues performed an intervention study involving eighty female patients with FPHL to evaluate the efficacy of oral antiandrogen therapy in the management of women with FPHL. Forty patients received spironolactone $200 \mathrm{mg}$ daily and 40 received cyproterone acetate, either $50 \mathrm{mg}$ daily or $100 \mathrm{mg}$ for 10 days per month if premenopausal. This study showed no significant difference in the results or the trend between spironolactone and cyproterone acetate. Thirty-five (44\%) women had hair regrowth, 35 (44\%) had no clear change in hair density before and after treatment, and only $10(12 \%)$ experienced continuing hair loss during the treatment period [66].

\subsubsection{Alopecia Areata}

Treatment is not mandatory considering it a benign condition. Spontaneous remissions and recurrences are common. Some therapeutic agents can be effective. This list includes systemic, intralesional and topical steroids under occlusion and topical immunotherapy with squaric acid dibutylester or diphencyprone [67-69].

\subsubsection{Chemotherapy Induced Alopecia}

Scalp cooling is as a method of preventing hair loss during chemotherapy and it has been discussed by several authors as an effective option [70,71]. Topical $2 \%$ minoxidil as a therapy for accelerating regrowth after chemotherapy has also proven to shorten the baldness period [72]. Psychological support, education, and self-care strategies are important components of any management approach [73].

\subsubsection{Trichotillomania}

Behavior therapy and pharmacotherapy are the most efficacious treatments for adult trichotillomania and have shown significant reductions in hair pulling over the short term. [74] Pharmacotherapy agents include selective serotonin inhibitors at high dosage and domipramine.
Recent developments in pharmacotherapy have suggested that other medications such as opioid blockers, atypical neuroleptics, and glutamate modulators hold promise as treatment for trichotillomania. [75]

\subsection{Telogen Effluvium}

\subsubsection{Iron Supplementation}

Female patients without systemic inflammation or other underlying disorders, serum ferritin levels below or equal to $30 \mathrm{ng} / \mathrm{mL}$ are strongly associated with telogen hair loss [76,77]. Iron supplementation with oral iron sulphate is recommended until a serum ferritin level of $70 \mathrm{ng} / \mathrm{ml}$ is achieved [4].

\subsubsection{Biotin Supplementation}

Biotin also known as vitamin $\mathrm{H}$ or coenzyme $\mathrm{R}$ has been shown to improve clinical appearance and combing problems in patients with uncombable hair syndrome [78]. A study performed by Shelley and colleagues showed the effectiveness of the biotin treatment in increasing the root strength, in making the scaling disappear, and in accelerating the growth rate, hence the hair became more pliable and combable. The recommended supplementation is $5 \mathrm{mg}$ daily [78].

\subsubsection{Cysteine Supplementation}

It is unclear whether cysteine supplements will improve the quality of hair and the growth cycle. Available clinical data do not prove or disprove this theory. The recommended dosage is $500 \mathrm{mg}$ daily.

\section{REFERENCES}

[1] J. V. Schmitt, C. F. Ribeiro, F. H. Souza, E. B. Siqueira and F. R. Bebber, "Hair Loss Perception and Symptoms of Depression in Female Outpatients Attending a General Dermatology Clinic," Anais Brasileiros de Dermatologia, Vol. 87, No. 3, 2012, pp. 412-417. doi:10.1590/S0365-05962012000300010

[2] S. B. Shrivastava, "Diffuse Hair Loss in an Adult Female: Approach to Diagnosis and Management," Indian Journal of Dermatology, Venereology and Leprology, Vol. 75, No. 1, 2009, pp. 20-28. doi:10.4103/0378-6323.45215

[3] M. B. Chartier, D. M. Hoss and J. M .Grant-Kels, “Approach to the Adult Female Patient with Diffuse Nonscarring Alopecia," Journal of the American Academy of Dermatology, Vol. 47, No. 6, 2002, pp. 809-818. doi: $10.1067 / \mathrm{mjd} .2002 .128771$

[4] A. Tosti, B. M. Piraccini, A. Sisti and B. Duque-Estrada "Hair Loss in Women," Minerva Ginecologica, Vol. 61, No. 5, 2009, pp. 445-52

[5] E. B. Hawryluk and J. C. English, "Female Adolescent Hair Disorders," Journal of Pediatric and Adolescent Gynecology, Vol. 22, No. 4, 2009, pp. 271-281. doi:10.1016/j.jpag.2009.03.007 
[6] A. L. Mounsey and S. W. Reed, "Diagnosing and Treating Hair Loss," American Family Physician, Vol. 80, No. 4, 2009, pp. 356-362.

[7] J. Shapiro, M. Wiseman and H. Lui "Practical Management of Hair Loss," Canadian Family Physician, Vol. 46, No. 7, 2000, pp. 1469-1477.

[8] F. Mulinari-Brenner and W. F. Bergfeld, "Hair Loss: An Overview," Dermatology Nursing, Vol. 13, No. 4, 2001, pp. 269-272, 277-278.

[9] H. H. Celik, H. Tore, S. Tunali, I. Tatar and M. M. Aldur, "Light and Scanning Electron Microscopic Examination of Hair in Griscelli Syndrome," Saudi Medical Journal, Vol. 28, No. 8, 2007, pp. 1275-1277.

[10] V. V. Smith, G. Anderson, M. Malone and N. J. Sebire "Light Microscopic Examination of Scalp Hair Samples as an Aid in the Diagnosis of Pediatric Disorders: Retrospective Review of More Than 300 Cases from a Single Center," Journal of Clinical Pathology, Vol. 58, No. 12, 2005, pp. 1294-1298. doi:10.1136/jcp.2005.027581

[11] K. A Adya, A.C Inamadar, A. Palit, R. Shivanna and N. S Deshmukh, "Light Microscopy of the Hair: A Simple Tool to 'Untangle' Hair Disorders," International Journal of Trichology, Vol. 3, No. 1, 2011, pp. 46-56. doi:10.4103/0974-7753.82124

[12] R. Paus and K. Foitzik, "In Search of the 'Hair Cycle clock': A Guided Tour," Differentiation, Vol. 72, No. 9-10, 2004, pp. 489-511. doi:10.1111/j.1432-0436.2004.07209004.x

[13] M. Kimura-Ueki, Y. Oda, J. Oki, A. Komi-Kuramochi, E. Honda, M. Asada, M. Suzuki and T. Imamura, "Hair Cycle Resting Phase is Regulated by Cyclic Epithelial FGF18 Signaling," Journal of Investigative Dermatology, Vol. 132, No. 5, 2012, pp. 1338-1345. doi:10.1038/jid.2011.490

[14] M. Courtois, G. Loussouarn, C. Hourseau and J. F. Grollier, "Hair Cycle and Alopecia," Skin Pharmacology, Vol. 7, No. 1-2, 1994, pp. 84-89. doi:10.1159/000211279

[15] S. Harrison and R. Sinclair, "Telogen Effluvium," Clinical and Experimental Dermatology, Vol. 27, No. 5, 2002, pp. 389-395. doi:10.1046/j.1365-2230.2002.01080.x

[16] O. T. Norwood, "Incidence of Female Androgenetic Alopecia (Female Pattern Alopecia)," Dermatologic Surgery, Vol. 27, No. 1, 2001, pp. 53-54. doi:10.1111/j.1524-4725.2001.00124.x

[17] R. Sinclair, M. Patel, T. L. Dawson Jr., A. Yazdabadi, L. Yip, A. Perez and N. W. Rufaut, "Hair Loss in Women: Medical and Cosmetic Approaches to Increase Scalp Hair Fullness," British Journal of Dermatology, Vol. 165, Suppl. 3, 2011, pp. 12-18. doi:10.1111/j.1365-2133.2011.10630.x

[18] V. H. Price, "Androgenetic Alopecia in Women," Journal of Investigative Dermatology Symposium, Vol. 8, No. 1, 2003, pp. 24-27. doi:10.1046/j.1523-1747.2003.12168.x

[19] V. K. Soni, "Androgenic Alopecia: A Counterproductive Outcome of the Anabolic Effect of Androgens," Medical Hypotheses, Vol. 73, No. 3, 2009, pp. 420-426. doi:10.1016/j.mehy.2009.03.032

[20] D. A.Whiting, "Male Pattern Hair Loss: Current Under- standing," International Journal of Dermatology, Vol. 37, No. 8, 1998, pp. 561-566,

[21] C. Jamin, "Androgenetic Alopecia," Annales De Dermatologie Et De Venereologie, Vol. 129, 2002, pp. 801-803.

[22] H. Zaun, "Influence of Contraceptive Hormones on Hair Growth," Deutsche Medizinische Wochenschrift, Vol. 103, No. 6, 1978, p. 240.

[23] H. Zaun, "Skin Changes from Taking Hormonal Contraceptives," Medizinische Monatsschrift für Pharmazeuten, Vol. 4, No. 6, 1981 pp. 161-165.

[24] H. Paterson, J. Clifton, D. Miller, J. Ashton and M. Harrison-Woolrych, "Hair Loss with Use of the Levonor-gestrel Intrauterine Device," Contraception, Vol. 76, No. 4, 2007, pp. 306-309. doi:10.1016/i.contraception.2007.06.015

[25] D. Wasserman, D. A. Guzman-Sanchez, K. Scott and A. McMichael, "Alopecia Areata," International Journal of Dermatology, Vol. 46, No. 2, 2007, pp. 121-131. doi:10.1111/j.1365-4632.2007.03193.x

[26] F. M. Delamere, M. J. Sladden, H. M. Dobbins and J. Leonardi-Bee, "Interventions for Alopecia Areata," Cochrane Database of Systematic Reviews, No. 2, 2008, Article ID: CD004413. doi:10.1002/14651858.CD004413.pub2

[27] A. Gilhar and R. S. Kalish, "Alopecia Areata: A Tissue Specific Autoimmune Disease of the Hair Follicle," Autoimmunity Reviews, Vol. 5, No. 1, 2006, pp. 64-69. doi:10.1016/j.autrev.2005.07.001

[28] S. Madani and J. Shapiro, "Alopecia Areata Update," Journal of the American Academy of Dermatology, Vol. 42, No. 4, 2000, pp. 49-66.

[29] M. J. García-Hernández, S. Ruiz-Doblado, A. RodriguezPichardo and F. Camacho, "Alopecia Areata, Stress and Psychiatric Disorders: A Review," The Journal of Dermatology, Vol. 26, No. 10, 1999, pp. 625-632.

[30] S. Ruiz-Doblado, A. Carrizosa and M. J. García-Hernández, "Alopecia Areata: Psychiatric Comorbidity and Adjustment to Illness," International Journal of Dermatology, Vol. 42, No. 6, 2003, pp. 434-437. doi:10.1046/j.1365-4362.2003.01340.x

[31] H. Khalaf, H. Negmi, G. Hassan, M. Al-Sebayel, "Postoperative Alopecia Areata: Is Pressure-Induced Ischemia the Only Cause to Blame?" Transplantation Proceedings, Vol. 36, No. 7, 2004, pp. 2158-2159. doi:10.1016/j.transproceed.2004.08.126

[32] R. M. Trüeb, "Chemotherapy-Induced Hair Loss," Skin Therapy Letter, Vol. 15, No. 7, 2010, pp. 5-7.

[33] D. Gude, "Tackling Chemotherapy-Induced Alopecia," International Journal of Trichology, Vol. 4, No. 1, 2012, pp. 47-48. doi:10.4103/0974-7753.96098

[34] I. R. Kim, J. Cho, E. K. Choi, I. G. Kwon, Y. H. Sung, J. E. Lee, S. J. Nam and J. H. Yang, "Perception, Attitudes, Preparedness and Experience of Chemotherapy-Induced Alopecia among Breast Cancer Patients: A Qualitative Study," Asian Pacific Journal of Cancer Prevention, Vol. 13, No. 4, 2012, pp. 1383-1388. doi:10.7314/APJCP.2012.13.4.1383

[35] H. Roe, "Chemotherapy-Induced Alopecia: Advice and 
Support for Hair Loss," British Journal of Nursing, Vol. 20, No. 10, 2011, pp. S4-S11.

[36] N. Shoenfeld, O. Rosenberg, M. Kotler and P. N. Dannon, "Tricotillomania: Pathopsychology Theories and Treatment Possibilities," The Israel Medical Association Journal, Vol. 14, No. 2, 2012, pp. 125-129.

[37] C. A. Flessner, V. S. Knopik and J. McGeary, "Hair Pulling Disorder (Trichotillomania): Genes, Neurobiology, and a Model for Understanding Impulsivity and Compulsivity," Psychiatry Research, Vol. 199, No. 3, 2012, pp. 151-158. doi:10.1016/j.psychres.2012.03.039

[38] G. Hamdan-Allen, "Trichotillomania in Childhood," Acta Psychiatrica Scandinavica, Vol. 83, No. 4, 1991, pp. 241243. doi:10.1111/j.1600-0447.1991.tb05532.x

[39] G. L. Hanna, "Trichotillomania and Related Disorders in Children and Adolescents," Child Psychiatry and Human Development, Vol. 27, No. 4, 1997, pp. 255-268. doi:10.1007/BF02353354

[40] M. E. Franklin, C. A. Flessner, D. W. Woods, N. J. Keuthen, J. C. Piacentini, P. Moore, et al., "The Child and Adolescent Trichotillomania Impact Project: Descriptive Psychopathology, Comorbidity, Functional Impairment, and Treatment Utilization," Journal of Developmental and Behavioral Pediatrics, Vol. 29, No. 6, 2008, pp. 493500. doi:10.1097/DBP.0b013e31818d4328

[41] C. D. Labouliere and E. A. Storch, "Pediatric Trichotillomania: Clinical Presentation, Treatment, and Implications for Nursing Professionals," Journal of Pediatric Nursing, Vol. 27, No. 3, 2012, pp. 225-232. doi:10.1016/j.pedn.2011.01.028

[42] J. T. Headington, "Telogen Effluvium. New Concepts and Review," Archives of Dermatology, Vol. 129, No. 3, 1993, pp. 356-363. doi:10.1001/archderm.1993.01680240096017

[43] A. M. Kligman, "The Human Hair Cycle," The Journal of Investigative Dermatology, Vol. 33, 1959, pp. 307-316. doi:10.1038/jid.1959.156

[44] S. Harrison and R. Sinclair, "Telogen Effluvium," Clinical and Experimental Dermatology, Vol. 27, No. 5, 2002, pp. 389-395. doi:10.1046/j.1365-2230.2002.01080.x

[45] A. Kligman, "Pathological Dynamics of Reversible Hair Loss in Humans," Archives of Dermatology, Vol. 83, 1961, pp. 175-198.

[46] A. Tosti, B. M. Piraccini and D. J. van Neste, "Telogen Effluvium after Allergic Contact Dermatitis of the Scalp," Archives of Dermatology, Vol. 137, No. 2, 2001, pp. 187190.

[47] E. A. Olsen, K. B. Reed, P. B. Cacchio and L. Caudill, "Iron Deficiency in Female Pattern Hair Loss, Chronic Telogen Effluvium, and Control Groups," Journal of the American Academy of Dermatology, Vol. 63, No. 6, 2010, pp. 991-999. doi:10.1016/j.jaad.2009.12.006

[48] A. Rook and R. Dawber, "Diffuse Alopecia: Endocrine, Metabolic and Chemical Influences on the Follicular Cycle," Blackwell Science Publications, Oxford, 1982.

[49] W. F. Bergfeld and F. Mulinari-Brenner, "Shedding: How to Manage a Common Cause of Hair Loss," Cleveland Clinic Journal of Medicine, Vol. 68, No. 3, 2001, pp.

\section{6-261. doi:10.3949/ccjm.68.3.256}

[50] R. Paus, V. A. Botchkarev, N. V. Botchkareva, L. Mecklenburg, T. Luger and A. Slominski, "The Skin POMC System (SPS). Leads and Lessons from the Hair Follicle," Annals of the New York Academy of Sciences, Vol. 885, 1999 , pp. 350-363.

doi:10.1111/j.1749-6632.1999.tb08690.x

[51] P. C. Arck, B. Handjiski, E. Hagen, R. Joachim, B. F. Klapp and R. Paus, "Indications for a 'Brain-Hair Follicle Axis (BHA)': Inhibition of Keratinocyte Proliferation and Up-Regulation of Keratinocyte Apoptosis in Telogen Hair Follicles by Stress and Substance P," FASEB Journal, Vol. 15, No. 13, 2001, pp. 2536-2538.

[52] A. Tosi, C. Misciali, B. M. Piraccini, A. M. Peluso and F. Bardazzi, "Drug-Induced Hair Loss and Hair Growth. Incidence, Management and Avoidance," Drug Safety, Vol. 10, No. 4, 1994, pp. 310-317. doi:10.2165/00002018-199410040-00005

[53] M. Gautam, "Alopecia Due to Psychotropic Medications," The Annals of Pharmacotherapy, Vol. 33, No. 5, 1999, pp. 631-637. doi:10.1345/aph.18346

[54] J. H. Eastham, "Postpartum Alopecia," The Annals of Pharmacotherapy, Vol. 35, No. 2, 2001, pp. 255-258. doi:10.1345/aph.10153

[55] L. Millikan, "Hirsutism, Postpartum Telogen Effluvium, and Male Pattern Alopecia," Journal of Cosmetic Dermatology, Vol. 5, No. 1, 2006, pp. 81-86. doi:10.1111/j.1473-2165.2006.00229.x

[56] E. A. Olsen, F. E. Dunlap, T. Funicella, J. A. Koperski, J. M. Swinehart, E. H. Tschen and R. J. Trancik, "A Randomized Clinical Trial of 5\% Topical Minoxidil versus 2\% Topical Minoxidil and Placebo in the Treatment of Androgenetic Alopecia in Men," Journal of the American Academy of Dermatology, Vol. 47, No. 3, 2002, pp. 377385. doi: $10.1067 / \mathrm{mjd} .2002 .124088$

[57] R. L. De Villez, "Androgenetic Alopecia Treated with Topical Minoxidil," Journal of the American Academy of Dermatology, Vol. 16, No. 3, 1987, pp. 669-672. doi:10.1016/S0190-9622(87)70085-1

[58] E. Arca, G. Açikgöz, H. B. Taştan, O. Köse and Z. Kurumlu, "An Open, Randomized, Comparative Study of Oral Finasteride and 5\% Topical Minoxidil in Male Androgenetic Alopecia," Dermatology, Vol. 209, No. 2, 2004, pp. 117-125. doi:10.1159/000079595

[59] K. J. McElwee and J. S. Shapiro, "Preventing Androgenic Alopecia," Skin Therapy Letter, Vol. 17, No. 6, 2012, pp. $1-4$.

[60] S. M. Stout and J. L. Stumpf, "Finasteride Treatment of Hair Loss in Women," The Annals of Pharmacotherapy, Vol. 44, No. 6, 2010, pp. 1090-1097. doi:10.1345/aph.1M591

[61] M. Iorizzo, C. Vincenzi, S. Voudouris, B. M. Piraccini and A. Tosti, "Finasteride Treatment of Female Pattern Hair Loss," Archives of Dermatology, Vol. 142, No. 3, 2006, pp. 298-302. doi:10.1001/archderm.142.3.298

[62] D. Rathnayake and R. Sinclair, "Innovative Use of Spironolactone as an Antiandrogen in the Treatment of Female Pattern Hair Loss," Dermatologic Clinics, Vol. 28, 
No. 3, 2010, pp. 611-618. doi:10.1016/j.det.2010.03.011

[63] D. Rathnayake and R. Sinclair, "Use of Spironolactone in Dermatology," Skinmed, Vol. 8, No. 6, 2010, pp. 328332.

[64] J. D. Peereboom-Wynia, A. H. Van der Willigen, T. Van Joost and E. Stolz, "The Effect of Cyproterone Acetate on Hair Roots and Hair Shaft Diameter in Androgenetic Alopecia in Females," Acta Dermato-Venereologica, Vol. 69, No. 5, 1989, pp. 395-398.

[65] R. Sinclair, M. Wewerinke and D. Jolley, "Treatment of Female Pattern Hair Loss with Oral Antiandrogens," British Journal of Dermatology, Vol. 152, No. 3, 2005, pp. 466-473. doi:10.1111/j.1365-2133.2005.06218.x

[66] K. H. Chang, S. Rojhirunsakool and L. J. Goldberg, "Treatment of Severe Alopecia Areata with Intralesional Steroid Injections," Journal of Drugs in Dermatology, Vol. 8, No. 10, 2009, pp. 909-912.

[67] A. Tosti, B. M. Piraccini, M. Pazzaglia and C. Vincenzi, "Clobetasol Propionate $0.05 \%$ under Occlusion in the Treatment of Alopecia Totalis/Universalis," Journal of the American Academy of Dermatology, Vol. 49, No. 1, 2003, pp. 96-98. doi:10.1067/mjd.2003.423

[68] R. Hoffmann and R. Happle, "Topical Immunotherapy in Alopecia Areata. What, How, and Why?" Dermatologic Clinics, Vol. 14, No. 4, 1996, pp. 739-744. doi:10.1016/S0733-8635(05)70400-9

[69] C. J. Van den Hurk, M. Peerbooms, L. V. van de Poll-Franse, J. W. Nortier, J. W. Coebergh and W. P. Breed, "Scalp Cooling for Hair Preservation and Associated Characteristics in 1411 Chemotherapy Patients-Results of the Dutch Scalp Cooling Registry," Acta Oncologica, Vol. 51, No. 4, 2012, pp. 497-504. doi:10.3109/0284186X.2012.658966

[70] P. K. Auvinen, U. A. Mähönen, K. M. Soininen, P. K. Paananen, P. H. Ranta-Koponen, I. E. Saavalainen, R. T. Johansson, M. Duvic, et al., "The Effectiveness of a Scalp Cooling Cap in Preventing Chemotherapy-Induced Alopecia," Tumori, Vol. 96, No. 2, 2010, pp. 271-275.
[71] C. E. Yeager and E. A. Olsen, "Treatment of Chemotherapy-Induced Alopecia," Dermatologic Therapy, Vol. 24, No. 4, 2011, pp. 432-442. doi:10.1111/j.1529-8019.2011.01430.x

[72] P. J. Hesketh, D. Batchelor, M. Golant, G. H. Lyman, N. Rhodes and D. Yardley, "Chemotherapy-Induced Alopecia: Psychosocial Impact and Therapeutic Approaches," Supportive Care in Cancer, Vol. 12, No. 8, 2004, pp. 543-549. doi:10.1007/s00520-003-0562-5

[73] W. E. Minichiello, R. L. O’Sullivan, D. Osgood-Hynes and L. Baer, "Trichotillomania: Clinical Aspects and Treatment Strategies," Harvard Review of Psychiatry, Vol. 1, No. 6, 1994, pp. 336-344. doi:10.3109/10673229409017100

[74] M. E. Franklin, K. Zagrabbe and K. L. Benavides, "Trichotillomania and Its Treatment: A Review and Recommendations," Expert Review of Neurotherapeutics, Vol. 11, No. 8, 2011, pp. 1165-1174.

[75] M. Moeinvaziri, P. Mansoori, K. Holakooee, Z. S. Naraghi and A. Abbasi, "Iron Status in Diffuse Telogen Hair Loss among Women," Acta Dermatovenerologica Croatica, Vol. 17, No. 4, 2009, pp. 279-284.

[76] D. H. Rushton, "Nutritional Factors and Hair Loss," Clinical and Experimental Dermatology, Vol. 27, No. 5, 2002, pp. 396-404. doi:10.1046/j.1365-2230.2002.01076.x

[77] V. Boccaletti, E. Zendri, G. Giordano, L. Gnetti and G. De Panfilis, "Familial Uncombable Hair Syndrome: U1trastructural Hair Study and Response to Biotin," Pediatric Dermatology, Vol. 24, No. 3, 2007, pp. E14-E16. doi:10.1111/j.1525-1470.2007.00385.x

[78] W. B. Shelley and D. Shelley, "Uncombable Hair Syndrome: Observations on Response to Biotin and Occurrence in Siblings with Ectodermal Dysplasia," Journal of the American Academy of Dermatology, Vol. 13, No. 1, 1985, pp. 97-102. doi:10.1016/S0190-9622(85)70150-8 